\title{
O Papel dos Polimorfismos de Nucleotídeo Único (SNPs) Pvu II e Xba I e das Pequenas Repetições em Tandem (STRs) (TA)n e (GT)n do Receptor de Estrogênio Alfa (ESR1) na Suscetibilidade do Câncer da Mama (BRCA)
}

\author{
The Role of Single Nucleotide Polymorphisms (SNPs) Pvu II and Xba I and Short \\ Tandem Repeats (STRs) (TA)n and (GT)n of Estrogen Alpha Receptor (ESRI) in \\ Breast Cancer (BRCA) Susceptibility
}

Karine Lourenzone de Araújo', Klesia Pirola Madeira², Renata Dalmaschio Daltoé3 ${ }^{3}$ Letícia Batista Azevedo Rangel${ }^{4}$, lan Victor Silva ${ }^{5}$

\section{Resumo}

O estrogênio é um hormônio esteroide sexual que possui efeito sobre o sistema reprodutor feminino e masculino. Esses efeitos são mediados principalmente pelas isoformas $\alpha$ e $\beta$ (ER $\alpha$ e $\beta)$, componente da superfamília de receptores nucleares que controlam a transcrição gênica. De fato, a resposta do gene ao estrogênio depende de muitos fatores, incluindo a avaliação dos subtipos de ER, os correguladores, o tempo de exposição ao estrogênio e a quantidade desse hormônio. Os processamentos (do inglês splicing) alternativos geram diversas variantes de RNAm de ESR1. As isoformas de RNAm com distintas regiôes 5 ' não traduzidas resultam na expressão da proteína ESR1 de diferentes tamanhos. Sabe-se que o gene ESR1 possui muitos sítios de polimorfismos que podem ser responsáveis por diferentes variantes alélicas da proteína, podendo alterar a função e a atividade dessa proteína e, então, resultar nas diferenças do efeito do estrogênio sobre o desenvolvimento de doenças. Existem vários fatores de risco relacionados ao BRCA, porém os polimorfismos do gene ESR1 contribuem de maneira expressiva para carcinogênese mamária. Os SNPs Pvu II e Xba I e os STRs (GT)n e (TA)n despertam curiosidade por se localizarem em regiōes não traduzidas do gene ESR1 e poderem estar relacionados a doenças de grande impacto, como o BRCA. Nota-se certa interferência desses polimorfismos nessa neoplasia, porém os resultados são divergentes. Contudo, é importante ampliar o conhecimento da genética do ESR1, pois existem evidências que suas propriedades interferem no desenvolvimento do BRCA.

Palavras-chave: Estrogênios; Receptor alfa de estrogênio polimorfismo genético; Neoplasias da mama

${ }^{1}$ Mestre em Biotecnologia pela Universidade Federal do Espírito Santo (UFES)

${ }^{2}$ Mestre em Biotecnologia pela UFES

${ }^{3}$ Mestre em Biotecnologia pela UFES

${ }^{4}$ Professora adjunta do Departamento de Ciências Farmacêuticas da UFES; Programa de Pós-graduação em Biotecnologia da UFES

${ }^{5}$ Professor adjunto do Departamento de Morfologia da UFES; Programa de Pós-graduação em Biotecnologia da UFES

Endereço para correspondência: Ian Victor Silva. Rua Begônia, 263 - Jardim Colorado - Vila Velha (ES), Brasil - CEP: $29104-680$.

E-mail: iasilv@yahoo.com 


\section{INTRODUÇÃO}

O estrogênio é um hormônio esteroide sexual que possui profundo efeito sobre o sistema reprodutor feminino e masculino, além de influenciar funções cognitivas e comportamento. Esses efeitos são mediados pelo ER, componente da superfamília de receptores nucleares que controlam a transcrição gênica. O ER consiste em um fator de transcrição ativado por ligante, composto por um domínio de ligação de estrogênio e um domínio de ligação de DNA. As duas principais isoformas são as $\operatorname{ER} \alpha$ e $\beta$, que apresentam distribuição e padrões de expressão genética distintos em diferentes tecidos. O ESR1 é expresso em uma variedade de tipos celulares e atua como um importante mediador na via de transdução de sinal, além de ser essencial para a resposta da ação do estrogênio.

Muitas variações na sequência do gene do ESR1, que podem alterar a atividade fisiológica e a estrutura da proteína, já foram reportadas; essas modificações possibilitam diferenças do efeito do estrogênio sobre o desenvolvimento de doenças. A associação de polimorfismos genéticos do ESR1 com o risco de doenças é objeto de grande interesse. Polimorfismos como os SNPs Pvu II e Xba I, e os microssatélites (GT)n e (TA)n despertam curiosidade, pois se localizam em regiōes não traduzidas, e são relacionados a doenças de grande impacto, como o BRCA.

No Brasil, estatísticas do Instituto Nacional de Câncer (INCA) revelam que o BRCA é a uma das principais causas de morte entre as mulheres ${ }^{1}$. A história familiar de BRCA é um importante fator de risco para essa enfermidade, já que $10 \%$ do total de casos dessa neoplasia são hereditários. De maneira geral, a grande maioria dos casos ocorre principalmente em mulheres pós-menopausadas, apresenta marcação positiva para os receptores de progesterona e estrogênio e não é associada à síndrome hereditária. Apesar de existem vários fatores de risco relacionados, tais como o uso de álcool e o estilo de vida, além de fatores epigenéticos, vários estudos apontam evidências de que os polimorfismos do gene ESR1 contribuem de maneira expressiva para a carcinogênese mamária. Em virtude das informaçōes supracitadas, o objetivo desta revisão é ampliar o conhecimento sobre os diversos processos relacionados ao ESR1 e auxiliar o entendimento dos possíveis eventos que os polimorfismos SNPs Pvu II, Xba I, e os microssatélites (GT)n e (TA)n do gene ESR1 utilizam para influenciar o surgimento e progressão do BRCA.

\section{METODOLOGIA}

A pesquisa bibliográfica foi a metodologia escolhida; foram utilizados como fonte de pesquisa as bases de dados do MEDLINE, PubMed, Portal periódico da CAPES (Coordenação de Aperfeiçoamento de Pessoal de Nível Superior) e livros.

\section{O ESTROGÊNIO E SEUS RECEPTORES}

O estrogênio é um hormônio esteroide, reconhecido como regulador do crescimento, diferenciação e metabolismo em mamíferos. As células da teca ovariana são as principais fontes de estrogênio nas mulheres prémenopausadas, pois produzem andrógeno que são transformados em estrogênio pela enzima aromatase nas células granulosas dos ovários. Durante a menopausa, a principal fonte desse hormônio é extragonadal, sendo o tecido adiposo, o qual expressa as enzimas aromatase e 17 beta-hidroxiesteroide, o principal responsável pela produção de estrogênio. Esse hormônio atinge muitos órgãos, tais como: cérebro, coração, ossos, mama, útero e próstata. Nas mulheres, o estrogênio é requerido para o desenvolvimento da vagina, do útero e das trompas uterinas, bem como as características sexuais secundárias e o comportamento. Estudos de DNA Microarray mostraram que o estrogênio afeta a transcrição de centenas de genes em diversas linhagens e tipos celulares $^{2}$. O perfil de expressão de genes muda em vários estágios de desenvolvimento e estado de doença ${ }^{3}$. De fato, a resposta tecidual ao estrogênio depende de muitos fatores, incluindo a avaliação dos subtipos de ER, os correguladores, o tempo de exposição ao estrogênio e a quantidade de estrogênió ${ }^{4}$.

O ER é membro da superfamília dos receptores nucleares dos mamíferos, muitos dos quais regulam a expressão de genes de maneira dependente de ligante. Esse receptor age como um fator de transativação mediada através da ligação com o estrogênio em ambos os sexos, sendo que essa proteína apresenta seis domínios distintos com funções específicas. $\mathrm{O}$ estrogênio, devido à sua alta lipossolubilidade, atravessa facilmente a membrana celular e liga-se ao ER solúvel, com alta afinidade, que está usualmente localizado no citoplasma. O ER encontra-se, em sua forma inativa no citosol, ligado a um complexo inibidor que possui chaperonas, como as proteínas de choque térmico Hsp90 e Hsp70. A fixação do ligante com o receptor no domínio carbóxiterminal, que é o de maior variabilidade, faz com que a proteína Hsp90 se dissocie, ativando o receptor pela exposição do seu sítio de ligação ao DNA. O ER ativado migra para dentro do núcleo, onde pode agir direta ou indiretamente provocando ações genômicas. 
O ER pode atuar diretamente ligando-se a um elemento de resposta ao estrogênio (ERE) anterior (do inglês upstream) a um gene alvo. Um ERE típico é uma sequência de $15 \mathrm{pb}$, compreendendo $6 \mathrm{pb}$ que formam um palíndromo, separados por quaisquer $3 \mathrm{pb}$, onde o ER se liga a uma versão especial de dedo de zinco. $O$ ER também pode operar indiretamente através da interação proteína-proteína, por meio da proteína ativadora 1 (AP-1) ou SP-1, na região promotora do gene que responde ao estrogênio. Outra maneira indireta de agir em genes que não possuem ERE é pela modulação de atividade de outros fatores de transcrição, como a proteína NF- $\kappa B$. A atuação do $\mathrm{ER}$, seja de maneira direta ou indireta, resulta no recrutamento de proteínas correguladoras (coativadoras ou correpressoras) para a região promotora, aumentando ou diminuindo os níveis de RNAm, associado à produção de uma proteína e à uma resposta fisiológica. Isso indica que a regulação da transcrição não pode ser considerada como processo independente baseado na cromatina, mas deve ser acoplada a muitos outros eventos celulares, que são realizados por muitos grupos distintos de fatores.

Há evidências de que o ESR1 pode também provocar ações não genômicas ${ }^{5}$. Em muitas dessas ações, a maquinaria transcricional não participa e, em vários desses processos, receptores situados na membrana plasmática podem estar envolvidos tanto nas vias de sinalização celular como no funcionamento de canais de cálcio e potássio, proteínas $\mathrm{G}$ e receptores acoplados a estas, cascatas da tirosino kinases PI3K e MAPK ${ }^{6}$. A interação do ESR1 com moléculas como NFkB, PI3K e MAPK indicam que esse receptor pode agir indiretamente através dessas moléculas na carcinogênese mamária. A expressão proteica do ESR1 é usada na prática clínica como um indicador para selecionar a hormonioterapia para pacientes acometidas de BRCA e a perda da expressão desse receptor é frequentemente associada à baixa sobrevivência dessas pacientes.

\section{ORGANIZAÇÃO GENÔMICA E CONTROLE DA EXPRESSÃO DO ESR1}

A expressão do ESR1 humano tem sido revelada bem complexa, envolvendo até sete promotores e oito éxons codificantes, totalizando em $450 \mathrm{~Kb}$ do cromossomo 6 . Diversas variantes de RNAm de ESR1 foram reportadas e alguns grupos de isoformas já foram identificados. A organização genômica da região promotora do ESR1 humano exibe importante função nos múltiplos eventos de processamentos alternativos (do inglês splicing). Algumas variantes de RNAm do ESR1 são produzidas pelo uso de promotores alternativos, resultando em isoformas de RNAm que diferem somente na região 5' não traduzida ${ }^{7}$.

Todas essas isoformas de RNAm com distintas regiōes $5^{\prime}$ não traduzidas resultariam na expressão da proteína ESR1 de tamanho $66 \mathrm{KDa}$. Entretanto, transcritos de RNAm que codificam proteínas de 66 $\mathrm{kDa}$ não são a única possibilidade, já que três formas variantes de ESR1 de 66, 46 e 39 kDa são expressas em osteoblastos, indicando processamento alternativo desse gene em pelo menos alguns tecidos. Isso mostra que o uso de promotores alternativos contabiliza a diferencial expressão de ESR1 em uma ampla variedade de tecidos ${ }^{8}$.

Existe o questionamento de como múltiplos promotores são mais firmemente regulados quando comparados a apenas um promotor. Há diversas explicações para tanto: 1) diferentes tecidos usam diferentes promotores; e/ou 2) diferentes promotores são usados em diferentes estágios de desenvolvimento; e/ou 3) transcritos produzidos de vários promotores sofrem diferentes processamentos alternativos, resultando em transcritos que codificam várias isoformas da proteína? .

O estudo da geração das variantes de RNAm do ESR1, bem como das isoformas da proteína, é complexo e requer ainda muitas pesquisas para que exista a plena compreensão dos mecanismos moleculares que envolvem todo esse tema. Nota-se, entretanto, que os polimorfismos do ESR1 localizados na região promotora desse gene podem exercer influência sobre os diversos processamentos alternativos e sobre a expressão proteica do ESR1. Esses polimorfismos, consequentemente, podem influenciar o surgimento e a progressão de doenças responsivas ao estrogênio, como muitos BRCAs.

\section{POLIMORFISMOS GENÉTICOS DO ESR1}

Muitos genes contêm variações nas sequências no genoma humano. Em geral, a forma mais comum da sequência é chamada de alelo tipo-selvagem e a sequência menos comum é chamada de alelo raro. A variação genômica das sequências pode ter duas formas: mutação (frequência $<\%$ ) e polimorfismo (frequência $>1 \%$ ). No campo da oncologia, dois tipos de polimorfismos são estudados extensivamente: SNPs e STRs.

Atualmente, a triagem genética do lócus do gene ESR1 revelou a existência de muitos sítios de polimorfismos (Figura 1) que podem ser responsáveis por diferentes variantes alélicos da proteína, podendo alterar a função e a atividade dessa proteína e, então, resultar nas diferenças do efeito do estrogênio sobre o desenvolvimento de doenças, como o BRCA. 
Os polimorfismos genéticos do ESR1 mais estudados são o microssatélite (TA)n e os SNPs Pvu II e Xba I, enquanto o microssatélite (GT)n é um dos mais recentes polimorfismos encontrados no gene ESR1. Esses polimorfismos estão localizados em regiões não codificantes do ESR1 e podem interferir na modulação da transcrição desse gene, pois, tanto no primeiro íntron do gene, onde se localizam os SNPs Pvu II e Xba I, como na região promotora, onde se localizam a repetição (TA)n e (GT)n (Figura 1), usualmente contêm um largo número de sequências regulatórias. Essa modulação pode aumentar ou diminuir o risco de doenças de grande impacto, como o BRCA. A análise de polimorfismos genéticos do ESR1 envolvidos na carcinogênese representa uma das mais estimulantes áreas da pesquisa genética no BRCA. Algumas dessas variantes genéticas são consideradas fatores de risco e podem interferir em diversos mecanismos de transformação das células mamárias.

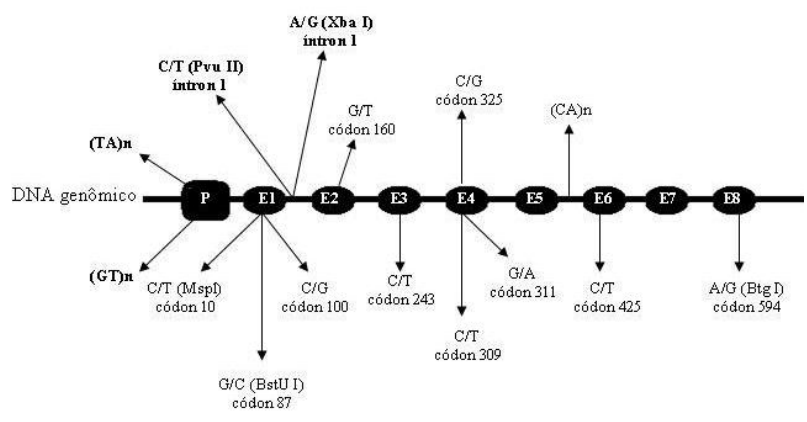

Figura 1: Polimorfismos do ESR 1

\section{a) MicrossatÉLITES (GT)N E (TA)N}

Nucleotídeos alinhados, em curtas repetições, organizados sequencialmente - STR short tandem repeats -, ou microssatélites, apresentam repetiçôes com unidade básica de 2-6pb e o polimorfismo está baseado no número de repetições. O número de repetições em um loci varia de maneira polimórfica entre os indivíduos e, devido ao fato de essas sequências estarem inseridas de forma estável, elas podem servir como marcadores polimórficos no rastreamento de linhagens paternas, além de se mostrarem extremamente úteis na prática forense.

A repetição de dinucleotídeo (TA)n (n sendo o número de repetiçôes), situada na região promotora, é localizada $1 \mathrm{~kb}$ anterior ao primeiro éxon a $-1118 \mathrm{pb}$ do início do sítio de transcrição ${ }^{10}$. A STR (GT)n foi notada mais tarde também na região promotora do gene ESR1. O microssatélite (GT)n é localizado a 6627bp anterior à região de início do sítio de transcrição do éxon $1^{11}$.

A função e o impacto das STRs não codificadas, como (GT)n e (TA)n, sobre a transcriçãao de genes, são um assunto ainda nebuloso que estimula os pesquisadores a avançar nos estudos. A concentração de STRs é aumentada dentro do genoma humano quando comparado a outros eucariontes. As STRs não transcritas têm sido mostradas na formação de nucleossomo nucleares e alguns podem agir como sítios de ligação de proteínas. Estudos revelam que um número aumentado de STRs localizados em íntrons interfere em processos de transcrição por seu efeito na estrutura secundária do $\mathrm{DNA}^{12}$ ou por outros mecanismos desconhecidos. Os polimorfismos STRs podem ter um impacto sobre a expressão gênica por influenciar a transcrição e/ou estabilidade do RNAm. A variabilidade nos tamanhos das STRs pode relatar pequeno erro derivado de variação/ perda de pareamento ou cópia inadequada da cromátide irmã. Além do mais, as STRs no gene ESR1 podem estar associadas às alteraçóes de genes adjacentes ao gene ESR1.

O polimorfismo de repetição $(\mathrm{GT})$ n localizado no gene ESR1 foi recentemente descoberto, portanto existem poucos estudos relacionados a esse polimorfismo STR. A distribuição dos alelos da repetição (TA)n difere levemente entre as populações de ancestrais europeus e asiáticos, com maiores picos de 14 e 15 repetiçôes, respectivamente ${ }^{13}$. Acredita-se que o número de repetiçóes (TA)n é importante para a transcrição do gene ESR1. Muitos diferentes promotores foram identificados no gene ESR1 e muitas localizaçôes de início de transcrição desses promotores estão sendo sugeridas. Em razão da STR (TA)n estar localizada entre as regiôes promotoras $\mathrm{A}$ e $\mathrm{B}$, é especulado se a variação alélica do tamanho da repetição (TA)n tem relevância fisiológica por afetar o uso do promotor. Interessantemente, um novo elemento regulador, parecido com um ERE, foi recentemente identificado na região 5 'do gene ESR1 humano, somente a 220 bases posteriores (do inglês dowstream) à região de microssatélite (TA)n. Esse elemento regulatório é composto por duas sequências de $7 \mathrm{pb}$ que juntas formam um perfeito palíndromo, similar a um ERE, separado por uma região de $21 \mathrm{pb}$. Análises de transfecção transiente demonstraram que essa sequência atua como um forte elemento acentuador em muitas linhagens celulares ${ }^{13}$.

\section{b) SNPS PVU II E XBA I}

Os polimorfismos do tipo SNP são os mais comuns polimorfismos dentro do genoma humano, eles possuem apenas variação, em uma base no interior de uma sequência de DNA que pode ser codificante ou não, e ocorrem aproximadamente uma vez a cada 1.350 pares de base no genoma humano. As análises de SNP têm diversos usos na genética do câncer, podem ser usadas 
para localizar genes causadores de cânceres familiares por análises de associação, além de serem utilizadas para determinar perda de heterozigozidade em cânceres humanos. Os SNPs são analisados pela técnica de Polimorfismo de Comprimento de Fragmento de Restrição (RFLP) e sequenciamento.

Os SNPs estão em grande número no gene do ESR1 humano, cerca de 2.334 são encontrados através de pesquisa no serviço SNP presente no site do National Center for Biotechnology Information ${ }^{14}$. Os SNPs Pvu II e Xba I localizados no íntron $1 \mathrm{a}-400 \mathrm{pb}$ anteriores do éxon 2 do gene ESR1 são os polimorfismos mais largamente estudados. O RFLP Pvu II detecta a substituição T-C na posição -397 antes do éxon 2 que é referido como T-397int1C, enquanto o RFLP Xba I detecta G-351int1A A $^{4}$ Os SNPs Pvu II e Xba I estão em uma área aparentemente não funcional do gene. Entretanto, um possível mecanismo funcional atribuído a esses polimorfismos inclui a mudança da expressão do gene ESR1 pela alteração da ligação dos fatores de transcrição e a influência sobre os processamentos alternativos do ESR1. Esses dois polimorfismos são separados somente por $50 \mathrm{pb}$ e estão em um forte desequilíbrio de ligação. Alelos $P$ e $X$ (ausência do sítio de restrição), tanto quanto os $p$ e $x$ (presença do sítio de restrição) estão fortemente associados um com o outro. Entretanto, haplótipo $p X$ não foi observado na maioria dos estudos, ao passo que $P x$ foi detectado, embora em uma frequência pequena, indicando que o desequilíbrio não é completo e que cada recombinação ou múltiplas mutações têm ocorrido entre ou perto desses dois sítios polimórficos ${ }^{13}$. Recentemente, Herrington et al. ${ }^{15}$ notaram que a transição $\mathrm{T} \rightarrow \mathrm{C}$ associada com a perda do sítio Pvu II resulta em um potencial sítio de ligação para o fator de transcrição myb, que, na presença de Bmyb, é capaz de aumentar 10 vezes a transcrição in vitro de um gene repórter formado posterior ao polimorfismo. Em algumas ocasiōes, então, a presença do alelo $\mathrm{P}$ deve amplificar a transcrição do ESR $1^{13}$. Outras análises de potenciais elementos regulatórios de genes mostraram que o alelo $P$ interrompe um potencial reconhecimento do sítio (CAGCTG) para o fator de transcrição AP4, aumentando a possibilidade desse elemento polimórfico influenciar a regulação de genes ${ }^{16}$. Hirofumi Maruyama et al. ${ }^{17}$ mostraram uma pequena, mas significante, atividade acentuadora de um fragmento de $1.3 \mathrm{~kb}$ entre o íntron $1 \mathrm{e}$ o éxon 2 do gene ESR1 e demonstraram que essa atividade difere entre os haplótipos Pvu II e Xba I. A atividade acentuadora do alelo $x$ parece ser mais alta do que o alelo $X$. A possibilidade da expressão do ESR1 ser regulada de acordo com os polimorfismos conduz os pesquisadores a examinar a frequência de SNPs no gene ESR1 em pacientes com doenças que estão relacionadas ao estrogênio. Ainda que leves, diferenças étnicas na distribuição do genótipo de Pvu II e Xba I estão sendo descritas e são notadas importantes variaçōes quando os haplótipos são observados. A população asiática mostrou frequência aumentada do haplótipo $P x$ e uma frequência reduzida do haplótipo $P X$, em comparação com a população caucasiana de ancestrais europeus, enquanto em uma população africana o haplótipo $p x$ foi presente em baixa frequência.

\section{POLIMORFISMOS GENÉTICOS DO ESRI E O BRCA}

Diferentes polimorfismos foram descritos no ESR1 e são relacionados com diversas doenças humanas. Eles podem alterar a função e atividade dessa proteína ${ }^{13} \mathrm{e}$, então, resultar em diferenças do efeito do estrogênio sobre o desenvolvimento de enfermidades. Os polimorfismos desse receptor são relacionados não somente com doenças do aparelho reprodutor, mas também com osteoporose, doenças cardiovasculares, desordens que envolvem o sistema nervoso central e neoplasias malignas, como BRCA.

Já é evidente que há fatores genéticos específicos, os quais aumentam o risco do BRCA, porém somente 5\% dos casos são atribuídos a mutações em genes bem definidos de alta penetrância como: BRCAs 1 e 2, ATM, PTEN e p53. A grande parte desse risco é atribuída a variantes genéticas de baixa penetrância, tais como os polimorfismos genéticos. Estudos têm sido realizados acerca do polimorfismo de repetição (GT)n, recentemente notado na região promotora do gene do ESR1, para investigar sua possível associação com o risco de BRCA. Um total de 16 alelos de repetição foi observado, variando de $(\mathrm{GT})_{11}$ a $(\mathrm{GT})_{27}$. Entre eles, o alelo $(\mathrm{GT})_{16}$ está presente em $41,5 \%$ dos casos de BRCA e $37,6 \%$ dos controles ${ }^{18}$. Com relação a esse tipo de STR, os cinco alelos mais comuns são: $(\mathrm{GT})_{15},(\mathrm{GT})_{16},(\mathrm{GT})_{17},(\mathrm{GT})_{18}$ e $(\mathrm{GT})_{23}$; e, dentre esses alelos, o $(\mathrm{GT})_{18}$ aumenta o risco de morte e esse risco não se torna maior quando o indivíduo é homozigoto para o alelo ${ }^{19}$. Já outros estudos têm mostrado que pacientes com genótipo contendo os alelos $(\mathrm{GT})_{17} \mathrm{e}$ (GT) ${ }_{18}$ foram, em geral, associados a uma diminuição no risco de BRCA e à redução da expressão de receptor de progesterona ${ }^{20}$, valendo salientar que essa associação foi mais evidente entre mulheres pós-menopausadas. Nas mulheres pré-menopausadas, o risco reduzido de BRCA foi observado com duas cópias do alelo $(\mathrm{GT})_{17}$ ou $(\mathrm{GT}){ }_{18}{ }^{21}$. Boyapati et al. ${ }^{19}$ mostraram que a presença 
de um ou dois alelos $(\mathrm{GT})_{23}$ foi fortemente relacionada a tumores da mama ER negativos.

O STR (TA)n, situado na região promotora do ESR1, mostrou influência bem estabelecida em doenças cardiovasculares, na densidade mineral óssea, na falência familiar prematura de ovário e na endometriose, e tem sido recentemente associado ao risco de desenvolvimento de BRCA. Foi observado que combinações específicas de polimorfismos de receptores hormonais poderiam constituir um risco de câncer, mais do que seus respectivos genótipos analisados separadamente. Em virtude disso, o microssatélite (TA)n não tem sido analisado isoladamente. Iobagiu et al. ${ }^{21}$ mostraram que polimorfismos de repetição dos receptores de androgênio e das isoformas $\alpha$ e $\beta$ do ER, $(\mathrm{CAG}) \mathrm{n},(\mathrm{TA}) \mathrm{n}$ e $(\mathrm{CA}) \mathrm{n}$, respectivamente, contribuem juntos para o desenvolvimento do BRCA. Analisados separadamente, a associação dos genótipos dos receptores hormonais com essa neoplasia é fraca, mas uma combinação particular de $(\mathrm{CA}) \mathrm{n}$ com $\mathrm{n}<23$ repetições, (TA)n com $n>20$ repetições e (CAG)n com $\mathrm{n}<15$ repetições foi claramente associada com o risco de BRCA ${ }^{22}$. Outro estudo também encontrou um possível perfil genético característico do BRCA, quando analisados os microssatélites supracitados. Esse perfil aponta uma combinação das repetiçōes (CAG)n com $\mathrm{n} \geq 28$ (soma das repetiçõos dos dois alelos), (TA)n com $\mathrm{n}<23$ (um alelo) e (CA) n com $\mathrm{n}<23$ (um alelo) que suporta a ideia de uma ação associativa dos receptores hormonais com essa enfermidade ${ }^{22}$. De encontro a esses dados, outros estudos mostraram que a repetição (TA)n não apresentou significativo efeito no risco de BRCA.

Outros polimorfismos que apresentam associação com essa doença são os SNPs Pvu II e Xba I, caracterizados pela presença do sítio de ação dessas enzimas de restrição, representados pelos alelos " $p$ " e " $x$ ", respectivamente. Existem relatos de um aumento significativo no risco de BRCA na presença do genótipo $P p$ e $p p$, e essa associação é mais forte entre mulheres com história familiar de BRCA, o mesmo ocorre com as pacientes que apresentam o genótipo $X x$ ou $x x^{23}$. Ao encontro do estudo supracitado, outros autores relataram que a presença de um ou dois alelos $p$ foi associada com o risco de BRCA e que a maior taxa foi observada na combinação entre o genótipo $p p$ e $X x$.

Como o risco do BRCA é afetado pelos SNPs intrônicos Pvu II e Xba I do gene ESR1, permanece sem explicação. No entanto, existem possíveis explicações que incluem: a) o polimorfismo intrônico pode ser um desequilíbrio de ligação com alteração no éxon que afeta a função proteica do $E S R 1^{24}$; b) o polimorfismo do ESR1 Pvu II pode estar ligado com a alteração de outro gene não identificado, localizado junto ao gene do ESR1, que aumente o risco do BRCA; c) mudanças intrônicas na sequência do gene podem ter um impacto na expressão de outros genes por influenciar a transcrição e ou a estabilidade do RNAm desses genes ${ }^{25}$; d) alguns íntrons possuem sequências regulatórias, tais como acentuadores, que afetam o nível de expressão através da regulação transcricional ${ }^{21}$.

A análise de polimorfismos genéticos do ESR1 envolvidos na carcinogênese representa uma das mais estimulantes áreas da pesquisa genética do BRCA e, por isso, é largamente estudada. Apesar de os estudos não serem concordantes quanto aos genótipos que, de fato, influenciam no desenvolvimento do BRCA, é notório que algumas dessas variantes genéticas são consideradas fatores de risco e podem interferir em diversos mecanismos de transformação das células mamárias.

\section{CONCLUSÃO}

Nota-se que há interferência dos polimorfismos STRs (GT)n, (TA)n e dos SNPs PvuII e Xba I no BRCA, porém os resultados de alguns artigos são ainda controversos. Várias sugestôes têm sido feitas para justificar tais resultados, incluindo: 1) erro de genotipagem; 2) diferenças étnicas e ambientais entre as populaçōes; 3) diferenças na idade e no tempo de menopausa; 4) tamanho de amostra inadequada de estudos; 5) tratamentos farmacológicos prévios (tais como o uso de estrogênios); 6) tipo de estudo; e 7) seleção baseada na ausência de doença com a tendência de excluir mulheres acometidas dessas doenças ${ }^{13}$. Mesmo diante de resultados discordantes, é de grande importância o estudo do fator genético na predisposição de doenças multifatoriais responsivas ao estrogênio, como a maioria dos BRCAs, pois é necessário esclarecer a influência dos polimorfismos do gene ESR1 sobre essas enfermidades e sobre a expressão do ESR1.

\section{AGRADECIMENTOS}

Agradecemos aos amigos do Laboratório de Biologia Celular do Envelhecimento e do Laboratório de Biologia Celular do Câncer Humano da Universidade Federal do Espírito Santo pelo apoio e incentivo.

\section{Potencial Conflito de Interesses: Nada a Declarar \\ REFERÊNCIAS}

1. Instituto Nacional de Câncer (Brasil). Conteúdo 2008. [monografia da Internet]. Rio de Janeiro: INCA; 2008 
[citado em 2008 jan 15]. Disponível em: http:// www.inca.gov.br/ conteudo_view.asp?id=336.

2. Inoue A, Yoshida N, Omoto Y, Oguchi S, Yamori T, Kiyama $\mathrm{R}$, et al. Development of cDNA microarray for expression profiling of estrogen-responsive genes. J Mol Endocrinol 2002; 29:175-92.

3. Reese J, Das SK, Paria BC, Lim H, Song H, Matsumoto H, et al. Global gene expression analysis to identify molecular markers of uterine receptivity and embryo implantation. J Biol Chem 2001 Nov 23; 276(47):44137-45.

4. Hall JM., Mc Donnell DP. The estrogen receptor beta isoform (ER beta) of the human estrogen receptor modulates ER alpha transcriptional activity and is a key regulator of the cellular response to estrogens and antiestrogens. Endocrinology 1999; 140(12): 5566-78.

5. Kim HP, Lee JY, Jeong JK, Bae SW, Lee HK, Jo I. Nongenomic stimulation of nitric oxide release by estrogen is mediated by estrogen receptor alpha localized in caveolae. Biochem Biophys Res Commun 1999; 263: 257-62.

6. Deroo BJ, Korach KS. Estrogen receptors and human disease. J Clin Invest 2006; 116: 561-70.

7. Hirata S, Shoda T, Kato J, Hoshi K. Novel isoforms of the mRNA for human female sex steroid hormone receptors. J Steroid Biochem Mol Biol 2003; 83:25-30.

8. Brand H, Kos M, Denger S, Flouriot G, Gromoll J, Gannon $F$ et al. A novel promoter is involved in the expression of estrogen receptor a in human testis and epididymis. Endocrinology 2002 Sep;143(9):3397-404

9. Kos M, Reid G, Denger S, Gannon F. Minireview: genomic organization of the human era gene promoter region. Mol Endocrinol 2001; 15:2057-63.

10. Schuit SC, Oei HH, Witteman JC, Geurts Van Kessel CH, Van Meurs JB, Nijhuis RL, et al. Estrogen receptor alpha gene polymorphisms and risk of myocardial infarction. JAMA 2004; 291:2969-77.

11. Sand P, Luckhaus C, Schlurmann K, et al. Untagling the human estrogen receptor gene structure. J Neural Transm 2002;109:567-83.

12. Gebhardt F, Burger H, Brandt B. Modulation of EGFR gene transcripition by secondary structures, a polymorphic repetitive sequence and muttions-a link between genetics and epigenetics. Histol Histopathol 2000;56:367-73.

13. Cohn CS, Sullivan JA, Kiefer T, Hill SM. Identification of an enhancer element in the estrogen receptor upstream region: implications for regulation of ER transcription in breast cancer. Mol Cell Endocrinol 1999;158:25-36.
14. National Center for Biotechnology Information. SNP 2008. Estados Unidos da América: ncbi; 2008 [citado em ago 2008]. Disponível em: URL: http://www.ncbi.nlm.nih.gov/sites/ entrez.

15. Herrington DM, Howard TD, Brosnihan KB, et al. Common estrogen receptor polymorphism augments effects of hormone replacement therapy on $\mathrm{E}$-selectin but not $\mathrm{C}$-reactive protein. Circulation 2002 Apr 23;105(16):1879-82.

16. Albagha OM, McGuigan FE, Reid DM, Ralston SH. Estrogen receptor alpha gene polymorphisms and bone mineral density: haplotype analysis in women from the United Kingdom. J Bone Miner Res 2001; 16:128-34.

17. Maruyama H, Toji H, Harrington CR, et al. Lack of an association of estrogen receptor alpha gene polymorphisms and transcriptional activity with Alzheimer disease. Arch Neurol 2000 Feb; 57(2):236-40

18. Zhang W, Yu YY. Polymorphisms of short tandem repeat of genes and breast cancer susceptibility. Eur J Surg Oncol 2007; 33:529-34.

19. Boyapati SM, Shu XO, Ruan ZX, Cai Q, Smith JR, Wen W, et al. Polymorphisms in ER a Gene interact with estrogen receptor status in breast cancer survival. Clin Cancer Res 2005; 11:1093-8.

20. Curran JE, Lea RA, Rutherford S, Weinstein SR, Griffiths LR. Association of estrogen receptor and glucocorticoid receptor gene polymorphisms with sporadic breast cancer. Int J Cancer 2001; 95: 271-5.

21. Iobagiu C, Lambert C, Normand M, Genin C. Microsatellite profile in hormonal receptor genes associated with breast cancer. Breast Cancer Res Treat 2006; 95:153-9.

22. Anghel A, Raica M, Marian C, Ursoniu S, Mitrasca O. Combined profile of the tandem repeats $\mathrm{CAG}, \mathrm{TA}$ and $\mathrm{CA}$ of the androgen and estrogen receptor genes in breast cancer. J Cancer Res Clin Oncol 2006;132:727-33.

23. Shen Y, Li D, Wu J, Zhang Z, Gao E. Joint Effects of the CYP1A1 MspI, ERa Pvu II, and ER a Xba I Polymorphisms on the Risk of Breast Cancer: Results from a PopulationBased Case-Control Study in Shanghai, China. Cancer Epidemiol Biomarkers Prev 2006; 15:342-47.

24. Kobayashi S, Inoue S, Hosoi T, Ouchi Y, Shiraki M, Orimo $\mathrm{H}$. Association of bone mineral density with polymorphism of the estrogen receptor gene. J Bone Miner Res 1996; 11:306-11.

25. Goessl C, Plaschke J, Pistorius S, Hahn M, Frank S, Hampl $\mathrm{M}$, et al. An intronic germline transition in the HNPCC gene hMSH2 is associated with sporadic colorectal cancer. Eur J Cancer 1997; 33:1869-74. 


\section{Abstract}

Estrogen is a steroidal sexual hormone that shows effect in both male and female reproductive tracts. Its effects are mediated mainly by the $\alpha$ and $\beta$ isoforms of the estrogen receptor (ER $\alpha$ and $\beta$ ), members of the superfamily nuclear receptor which controls gene expression. In fact, the gene's response to estrogen depends on many factors, including the assessment of subtypes of ER, the co-regulators, the time of exposure to estrogen and the amount of this hormone. Alternative processes (splicing) generates several variants of RNAm species of ESR1. The RNAm isoforms with distinct regions of 5' non-translated result in the expression of ESR1 protein of different sizes. It is known that the ESR1 gene has many polymorphic sites that may be responsible for such allelic variants of the protein, which may modify both function and activity of this protein and, therefore, show the observed differences of the estrogen effect on the disease development. There are several risk factors related to breast cancer (BRCA), but just recently, have the polymorphisms on the ESR1 gene been studied in this neoplasia. The single nucleotide polymorphisms (SNPs) known as Pvu II and Xba I and STRs (GT)n and (TA)n have intrigued the researcher because they are located within non-translated regions of the ESR1 gene and may also be related to BRCA. It has been noticed that such elements may interfere with this disease; however, the results are not very consistent. Nevertheless, it is important to increase the knowledge of the genetic of ESR1 because there is evidence that its properties interfere with the development of breast cancer.

Key words: Estrogens; Estrogen receptor alpha, polymorphism, genetic; Breast neoplasms 